\title{
The Limbo Atmosphere in operating room settings Caused by Disruptive Behaviors: A Qualitative Study
}

\section{Sahar Mirzaei}

Shaheed Beheshti University of Medical Sciences

Marzieh Pazokian ( Pazokian@sbmu.ac.ir)

Shaheed Beheshti University of Medical Sciences

Foroozan Atashzadeh-Shoorideh

Shaheed Beheshti University of Medical Sciences Research Institute for Gastroenterology and Liver Diseases

\section{Seyed Amir Hosein Pishgooie}

Aja University of Medical Sciences Faculty of Nursing

\section{Research article}

Keywords: Operating rooms, problem behavior, operating room nursing, content analysis

Posted Date: May 19th, 2020

DOI: https://doi.org/10.21203/rs.3.rs-28425/v1

License: (9) This work is licensed under a Creative Commons Attribution 4.0 International License. Read Full License 


\section{Abstract}

Background Operating room nurses are one of the groups frequently expose to Disruptive Behaviors in different situations in the operating rooms that have different impacts on them and their performance. Recognition of DBs and their effects can help to offer strategies for better management of these behaviors. This study aimed to explore the experiences of Iranian operating room nurses regarding Disruptive Behaviors in operating room settings.

Methods This is a descriptive qualitative study conducted in university hospitals in Tehran. The data were collected by deep semistructured interviews with a total number of 17 operating room nurses selected purposefully. Finally, the data were analyzed with the conventional content analysis approach.

Results Five categories were extracted from the study, including "activity in a poisonous atmosphere", "role subtraction", "escape to a safe margin", "adaptation to stay calm", and "Indirect confrontation". Finally, a theme was "struggle in a limbo Atmosphere caused by Disruptive Behaviors".

Conclusion Under great pressure of surgeon's Disruptive Behaviors, operating room nurses were struggling to maintain their balance and performance at possible. Considering the effect of Disruptive Behavior, it seems necessary to take training measures for improving team-working in operation room settings. Besides, monitoring and follow-up such behaviors according to negative effects is necessary.

\section{Background}

Disruptive Behaviors (DBs) are being raised as a major problem in health care systems, which are also more common among surgeons than other medical groups [1-3].

The American Medical Institute defines DBs that lead to a perceived threat for victims or witnesses and violation of the criteria of reasonable and respectful behavior[4], like verbal or physical interactions that can cause negative effects or potentially negative impacts on patient care[1]. As well, DBs refer to inappropriate actions or conflicts, which can occur intentionally or merely due to no awareness about its outcomes [5] that can consequently disrupt team performance and collaborations [6, 7].

DBs are very common in operating rooms (ORs). In a study by Villafranca 2019 [8] on 134 perioperative associations from seven countries, the median of the frequency exposing each employee in the operating room (OR) team to such behaviors had been reported by 61 times, in the last year. The prevalence rate had been also estimated by $97 \%$ at least 1-2 times a year and the overall prevalence rates had been 98\%, 97.9\%, 96.7\%, and 96.8\% in Canada, the United States, Brazil, and India; respectively.

Ian Fast 2020 in one other study had similarly reported the prevalence rate of such behaviors by $96 \%$ in 23 perioperative associations from seven countries and had indicated that almost $97 \%$ of individuals had not recounted all observed DBs [9]. In the study of Kusy and Holloway 2014, 77\% of nurses reported abuse from physicians [10], Moreover, Hosseinpour-Dalenjan et al 2017 also found the mean score of disrespect to nurses by physicians was higher

than in other groups [11].

In their study, Rosenstein and O'Daniel 2005 had noticed that $86 \%$ of nurses had encountered these behaviors, and physicians had additionally expressed that in half of their fellow workers had witnessed such behaviors.[12] Besides, Garth et al. 2019 had reported that the prevalence rate of unpleasant and uncivil behaviors with nurses by physicians was approximately $66 \%$ [13].

DBs as a major problem in health care systems have numerous negative consequences interfering with patient care, affecting both patient and personnel safety $[3,14,15]$, and cause increasing workplace stress and work burnout[12]. Responding to this stress also results in a range of behaviors and reactions such as fear, the tension in ORs, poor teamwork, as well as hostile environments [6].

Concerning the importance and the effects of DBs, the United States-based Joint commission in 2008 emphasized identifying and determining the severity of these behaviors which could seriously threaten patient safety, and also advise acting to alleviate or 
eliminate them. Health care provider organizations that pay no attention to these behaviors may thus endanger patient safety, expose themselves to dissatisfaction and petitions of personnel and patients, and help in developing such behaviors[16].

world health organization about Safe surgery says Although surgeries are conducted to improve patient health, major complications of surgical procedures have been thus far reported, so $3-16 \%$ of operations lead to permanent disability, and mortality reported by $5-10 \%$ in developing countries [17]. Therefore, such problems can be reduced by improving factors affecting safety such as minimizing stressful factors and boosting team performance.

Accordingly, stressful factors such as DBs with the impact of cognitive mechanisms such as memory can interfere with effective performance [18]. Therefore, early identification and follow-up of these behaviors having a significantly negative effect on patientrelated outcomes are vital [19]. Despite evidence about the unpleasant effects of these behaviors, as noted above, many organizations still leave such difficult conditions behind in recognizing and tracking these issues effectively [20].

Understanding how stressor-induced behavioral responses, such as DBs of surgeons, may affect surgical procedures and OR team members, is essential to moderate unwanted surgical incidents, to improve safety, and to better outcomes [21]. Thus, a better identifying of the nature, causes, and effects of DBs along with providing support for finding appropriate strategies to solve them in OR is crucial [20].

Few studies have so far examined emotional and behavioral responses to some stressors in OR, but interpersonal communications have been neglected even with efforts in recent decades to improve patient safety, to reduce damages, and to improve the outcomes $[18,22]$. Therefore, further research is needed to identify the problems associated with interpersonal behaviors for changing them. [23].

In this respect, in a quantitative study in Iran, the prevalence rate of DBs had been reported by $82 \%$. In this descriptive study, ORNs had mentioned the effects of these behaviors on creating negative consequences (78\%), threatening patient safety (27\%), and minimizing care quality (37\%) [21].

Despite high exposure of nurses with DBs by physicians [11] especially surgeons [24] and the necessity of accurate recognition of its effects [5], there are few studies on Disruptive Behavior (DB) in Iran also there is no study has been so far conducted with a qualitative approach to deep explore the effects of these behaviors from the perspective of Iranian ORNs. Given the cultural context and lack of precise information about DBs in Iran, there are many questions such as what is the experience of ORNs from DBs? What are the effects of DBs on ORNs? How ORNs perceive and how they react to or deal with these behaviors? On the other hand scrub and circulating nurses are key members of ORs, they can play diverse, multifaceted, and specialized roles in these environments and work in direct relationships with surgeons, they can even have a significant impact on the overall team performance and surgical consequences $[25,26]$.

Thus, obtaining their experiences about DBs in a qualitative approach provides a context for having profound cognition and a better understanding of effects, offering strategies, and interventions to improve team relations and teamwork outcomes. The purpose of this study was to explain Iranian ORNs' experiences about DBs.

\section{Methods}

\section{Study Design}

This is a descriptive qualitative study. Conventional content analysis as a qualitative approach was utilized in this study. Qualitative content analysis can be defined as a "research method for the subjective interpretation of the content of text data through the systematic classification process of coding and identifying themes or patterns" [27].

\section{Sampling And Recruitment}

Participants in this study were a total number of 17 ORNs working at the different university hospitals in Tehran, Iran, from February to December 2019, who were purposefully selected. The inclusion criteria were ORNs with at least one year of work 
experience as a scrub or circulating nurses and with a willingness to participate in the study.

\section{Data Collection}

Data Collection was done through semi-structured interviews in a quiet and private setting such as an empty and safe room in a hospital or wherever the participants felt at ease. Interviews continued until data saturation. On average, the interviews lasted 52 minutes. They started with a general question about experiencing or observing DBs and then followed by probing questions wherever necessary. During the interviews, nurses' experiences and observations regarding destructive behaviors were emphasized. Some of the interview questions were "Have you ever encountered or witnessed DBs by surgeons in ORs?" followed by exploratory questions such as "Please share your experience or observations about such behaviors. How did that affect you? Please explain more about it, please give an example" for more clarity and a better understanding of the problem. After obtaining written consent from the participants, the interviews were recorded by a tape recorder and transcribed verbatim at the earliest opportunity.

\section{Data Analysis}

Conventional content analysis was used to analyze the data according to the steps which were developed by Graneheim and Lundman 2004. Firstly, the interviews were listened and then transcribed immediately and were read several times to create a general understanding of the whole interview. Then, semantic units were determined and initial codes were assigned to each unit in the form of open coding. After that, the initial codes were merged into more general and more abstract Categories as based on their similarities and differences, lastly, the final theme was abstracted as the latent meaning of the data based on the relationship between the categories [28].

\section{Rigor}

To ensure the trustworthiness of the study four criteria were used. In this respect, credibility was met by long-term involvement and immersion with data through continuous reviews, frequent listening to interviews, spending enough time (11 months) to collect and analyze the data, and utilizing discussion in the research team. In order to gain data dependability or consistency of the findings, the extracted codes and categories were provided to a number of ORNs as well as external observers such as qualitative research experts to confirm their correctness. Participants with maximum diversity (ORNs with different levels of education, work experiences, genders, work shifts, and different hospitals) were used to reach confirmability. Furthermore, data transferability was achieved by transcribing the interviews immediately after their completion as well as providing an accurate and rich description of ORNs' experiences and citation of examples and quotations [29].

\section{Results}

The findings were obtained from interviews with a total number of 17 female and male participants including ORNs working in various ORs with a mean age of $36.6 \pm 9.78$ years and work experience of $13 \pm 7.25$ years, in different shifts with levels of education from undergraduate to postgraduate.

Eventually, 5 categories including (1) activity in a poisonous atmosphere, (2) role subtraction, (3) escape to a safe margin, (4) adaptation to stay calm, and (5) Indirect Confrontation, and finally a theme entitled "struggle in a limbo Atmosphere caused by Disruptive behaviors" extracted (Table 1). 
Table 1

Formation of Sub-categories, Categories, and theme

\begin{tabular}{|c|c|c|}
\hline Sub-categories & Main Categories & Theme \\
\hline $\begin{array}{l}\text { Bearing the burden of offensive and uncivil } \\
\text { behaviors at work }\end{array}$ & \multirow[t]{3}{*}{$\begin{array}{l}\text { Activity in a Poisonous } \\
\text { atmosphere }\end{array}$} & \multirow[t]{15}{*}{$\begin{array}{l}\text { Struggle in a Limbo atmosphere caused by } \\
\text { disruptive behaviors }\end{array}$} \\
\hline $\begin{array}{l}\text { Ignoring nurses' knowledge, experiences, and } \\
\text { assistance }\end{array}$ & & \\
\hline Profound psychological wounds & & \\
\hline Deviated focus from patients to surgeon & \multirow[t]{4}{*}{ Role subtraction } & \\
\hline Decreasing physical and mental performance & & \\
\hline Indifference and reduced commitment & & \\
\hline $\begin{array}{l}\text { Unfriendly behaviors and tension with fellow } \\
\text { workers }\end{array}$ & & \\
\hline Silence and reticence & \multirow[t]{2}{*}{ Escape to a safe margin } & \\
\hline Avoidance of disruptive situations & & \\
\hline Relying on moral values & \multirow[t]{4}{*}{ Adaptation to stay calm } & \\
\hline $\begin{array}{l}\text { Attempts to develop capabilities (skills and } \\
\text { spirit) }\end{array}$ & & \\
\hline $\begin{array}{l}\text { Trying to get support from authorities and co- } \\
\text { workers }\end{array}$ & & \\
\hline Attributing behaviors to external factors & & \\
\hline $\begin{array}{l}\text { Decreasing cooperation and no support from } \\
\text { surgeon }\end{array}$ & \multirow[t]{2}{*}{ Indirect confrontation } & \\
\hline Punishment of Surgeon & & \\
\hline
\end{tabular}

\section{Activity In A Poisonous Atmosphere}

"Activity in a poisoned atmosphere" included three concepts of "bearing the burden of offensive and uncivil behaviors at work", "Ignoring nurses' knowledge, experiences, and assistance", and "profound psychological wound".

\subsection{Bearing the Burden of Offensive and Uncivil Behaviors at Work}

This category was comprised of behaviors creating a sense of being humiliated, insulted, and blamed in front of others. These behaviors often contained the use of disrespectful words and body language to interact with nurses while working.

"We are performing surgeries for several hours with a surgeon. So, when there is not an instrument in the OR. We do not have it at all, he insults us with his look and says with a humiliating tone that ... we are lazy ... we do not help ... we do not work ... in this way, the work-related fatigue lasts for a long time."(Participant No.14).

\subsection{Ignoring Nurses' Knowledge, Experiences, And Assistance}

The nurses considered it a factor for discouragement because they were feeling upset that their knowledge and skills were usually ignored and the surgeons did not pay attention to them. They also complained about the overemphasis of some physicians on the distance between themselves and the nurses and found it also as a major factor of discouragement, work-related fatigue, and reluctance. 
"I think the only thing that may make work hard for me in my job is to devalue our work by some of the surgeons. Let me say, when a part of the body is bleeding and I am trying to help or even guide them, they say they themselves know about it very well."

(Participant No. 16).

Participant No. 10 had additionally added:

"When the resident started to adjust the light with the handle of the sterilized surgical light lamp, the surgeon warned him that was not their business but the circulating nurse and said that they needed their shoulders for surgery."

\subsection{Profound Psychological Wounds}

This category included a sense of sadness, unhappiness, depression, anger, stigma, as well as humiliation and, lack of motivation. Profound psychological wounds also referred to heavy emotional pressures caused by uncivil behaviors burdened on nurses for a long time, and affecting their emotions and spirit and ultimately their performance.

"When a surgeon has a bad behavior with a nurse, this behavior influence other also, and they try to keep a distance with the victim." (Participant No. 6).

Expressing a sense of frustration: "The surgeon treated me very badly in front of others. Now, two months have passed, but I am still sad and upset ... he dishonors me. I tell myself (in tears) I wish I had never chosen this field." (Participant No. 11).

\section{Role Subtraction}

Role Subtraction or in other words role negligence was comprised of the concepts of "deviated focus from patients to surgeon", "Decreasing physical and mental performance", and "indifference and reduced commitment to duties", "unfriendly behaviors and tension with co-workers".

\subsection{Deviated Focus From Patients To Surgeon}

Nurses had tried to appease the surgeons and paid more attention to their demands due to observing or confronting DBs, so an essential part of their function had been lost due to deviated focus towards the surgeon. In this category meeting surgeons' expectations, trying to satisfy surgeons was outweighed the patient's needs.

"The patient feels cold or there is no covering since I am afraid of surgeons to come and tell why the patient is not ready. I inevitably used catheter hastily and did not pay attention to this patient's need" (participant No. 5).

\subsection{Decreasing Physical And Mental Performance}

The given category consisted of stress, slow performance, decreased concentration, distractions, forgetfulness, and increased error. In this line, DBs could cause high levels of stress in nurses and more severe behaviors could have a more significant effect on their performance. For example, nurses suffered high levels of anxiety and stress, dysfunctions such as slowness or distraction, and an error occurred. "When the surgeon shouts or he is angry, I become more confused and make many more mistakes, in a way that the tools are at hand but I cannot find them. I feel stressed out." (Participant No. 11).

\subsection{Indifference And Reduced Commitment To Duties}

DBs, with profound effects on nurses' spirit, had led to a sense of discouragement and had consequently decreased sensitivity to some aspects of work and duties and, also inevitably reducing honesty. It was an effort to protect themselves against the pressure of such behaviors. 
"It has never happened to me, but I have seen some personnel arguing or being exposed to bad behavior, when they collect the instruments, they work careless and rough with equipment, with anger, some instruments are delicate, they break easily ..." (Participant No. 8).

I just remember that my fellow worker used an unsterile device because she afraid to say to the surgeon that it has become unsterile." (Participant No. 9)

\subsection{Unfriendly Behaviors And Tension With Co-workers}

Following DBs, nurses suffer from emotions such as sadness, worthlessness, and despair and consequently demonstrate aggressive behaviors or misbehaviors towards their fellow workers and sometimes perpetrate violence against them.

"As the surgeon talked to me badly, I rushed out of the OR and when my coworker asked me something, I talked to her badly and also treated her aggressively." (Participant No. 1).

\section{Escape To A Safe Margin}

The nurses had also used different strategy against DBs, as category extracted in this study, escape to a safety margin was a strategy to keep inner peace, to be less exposed to insults, and to find a way to reduce the incidence of DBs and being in a safe and tolerable state. This was the result of two sub-categories of "silence and reticence" and "avoidance of disruptive situations".

\subsection{Silence And Reticence}

Silence and reticence emerged following DBs whereas individuals had refused to express supportive or participatory ideas and opinions, and had gradually thought of being worthless and feared expressing opinions and suggestions, and caution in interacting with surgeons was created after commenting out and expose with DBs, and consequently, the person moved toward discouragement and silence.

"I used to help the surgeon in any way. If they failed to notice something and I realized it, I would like to say what to do. Now I do not say anything, I have nothing to do with them anymore,

I pass cautiously"(Participant No. 10).

Moreover, Participant No. 3 reiterated: "When my co-worker saw that the surgeon was doing the preps for the patient wrongly and warned him and then saw his behavior was bad, he said nothing more and did not go on and just said yes any way you know it."

\subsection{Avoidance Of Disruptive Situations}

Following observing or confronting disrespectful behaviors, the participants had also attempted to protect themselves by withdrawing from disruptive individuals and situation to reduce the effects of these behaviors and to protect their dignity. The participants had also distanced themselves from the mentioned individuals and had even refused to participate in their surgeries "After that harsh and nasty behavior, I promised myself I would not attend to his surgeries anymore. I did not like to work with him any longer. I told the manager not to put me in his room." (Participant No. 7).

\section{Adaptation To Stay Calm}

This was an effort to prevent recurrence and to reduce DB effects through some measures such as "Attempts to Develop Capabilities" (i.e. Skills and Spirit) and "trying to get support from the head nurse and fellow workers". They also prevented its negative effect on own emotions and performance through "attributing these behaviors to external factors" such as the surgeon's characteristic and "relying on moral values". 


\subsection{Relying On Moral Values}

The participants had tried to rely on ethical values such as conscientiousness and consider patients as an important member of their family to lower the negative effects of DBs.

" I always put the patients in the place of my darlings and say if I ignore them, someone else in another place will pay no heed to my mother. My conscience won't let me do that. "(Participant No.12).

\subsection{Attempts To Develop Capabilities (skills And Spirit)}

One of the reactions to minimize the incidence of DBs was nurses' efforts to improve capabilities and self-confidence in themselves and their fellow workers and to help promote their profession.

"I tried to read or to learn, for example, I increased my skills and broadened knowledge through watching surgical videos online." (Participants No. 3).

Participant No .9 also added:

"When my fellow worker is treated inappropriately, she loses her self-confidence ... she also fears to go into surgery. I try to give her self-confidence, tell her what to do, for example, I talk to her constantly to get rid of her flaws ..."

\subsection{Trying to Get Support from the head nurse and co-workers}

After DBs, the personnel were seeking support for self-defense and changing situations by raising the problems with their supervisors, heads of ORs, or in limited cases co-workers.

"After his behavior, I went to speak with the head nurse. I told him he had no right to behave me like this. He had no right to insult. Our head nurse said I would talk to him." (Participant No. 17)

\subsection{Attributing Behavior To External Factors}

According to this category, the nurses attributed DBs to the difficulty of surgical procedures and surgeons' behavioral characteristics but not relevant to themselves or their performance.

"Of course, well, their work is hard too ... it is close to the nerves, next to the arteries ... also he treats all in this way and I am not an exception. He is always in this mood ... everyone knows it." (Participant No. 14)

\section{Indirect Confrontation}

DBs had led to a variety of reactions by the personnel such as fights to maintain their status and position. The fight had been done to prove power, to change conditions, to prove the importance of its own role, and to improve interactions.

Although it had raised tensions to some extent in some times, it had been used as a coping strategy by the participants and included the concepts of reduced "cooperation and no support from surgeon" and "Punishment of Surgeon".

\subsection{Decreasing Cooperation And No Support From Surgeon}

Nurses can help surgeons by continuous watchful, observing, monitoring, and managing potential threats and prevent lifethreatening mistakes, and can cause the desired process and outcome of the surgeries, but following a confrontation with DBs, the nurses had tended towards decreasing cooperation and supporting from the surgeon. This mechanism was a way either to protect oneself or to show indirectly their objections. 
"he used to want something and I tried to immediately find even it in other rooms anyway, even if there was in shortage ... I would find it to help him do his job better, to do it faster ... but I do not do it now. "(Participant No. 16).

I was doing whatever to help surgeon, e.g., I have tied the stitches for him so quickly. Without his request, I had a better view of the operation site with the retractor, but, when he doesn't appreciate my help, I do not help him anymore." (Participant No. 4).

\subsection{Punishment Of Surgeon}

In some situations, participants for revealing their objection, to promote professional power, and to correct these behaviors had decided to punish the surgeon in various indirect ways. Indeed in this manner Punishment was considered as one type of retaliation.

"When he treats me like this, I get angry with him, I don't answer his greetings, and he will realize why I had done so, and I don't talk to him even until he comes to apologize." (Participant No. 2).

I was a circulating nurse. I did not give him a laparoscopic good lens, as he disrespected and devalued me. We had a good lens and it was up to me but I did not give it." (Participant No. 4).

\section{Discussion}

The purpose of this study was to explore ORNs' experiences about DBs. DBs in ORs that are often attributed to surgeons refer to one type of behavioral disorder that in various manner can have negative effects on outcomes related to patients and patient safety $[1,6]$. The findings in this study led to creating better visions about DBs and their effects on personnel emotions and performance and subsequently patient care.

The main theme of the present study was "struggle in a limbo Atmosphere caused by DBs", indicating the mental pressure tolerated by nurses and their efforts to reduce the incidence and pressure of such behaviors to mitigate the negative effects of these frustrating behaviors. The pressure had resulted from these behaviors had further led to various emotions and performances by the participants and could mainly have undesirable effects on the quality of patient care.

DBs by the surgeons were verbal and focused on aspects of insult, disrespect, blame, as well as an emphasis on the distance between physicians and nurses. Moreover, there was no tangible difference in the perception of these behaviors between male and female participants. However, the males had shown more reactions including reciprocations, retaliations, and arguments for changing situations, which might be due to more adaptive features of women than men as well as stereotypical behaviors [30].

Participant this study recognized the sense of Activity in a Poisonous atmosphere as an important impact of DB. The operating rooms naturally have a high-stress environment [31] therefor this pressure will be even greater under DBs [32]. The results of study showed that nurses who were exposed to disruptive and uncivil behaviors endured a lot of pressure.

In bearing the burden of offensive and uncivil behaviors at work subcategory, participants stated that they work under excessive pressure of DB which has many negative physical and psychological effects. Responses related to chronic stressors such as fatigue, fear, helplessness, anxiety, and worry as the negative impact of long time pressures with lack of support to be a factor for burnout [33] so it is important to pay attention to these intense and long-term pressures.

The most significant effects in Profound psychological wounds on nurses' emotions were the sense of sadness and worthlessness although, in the survey by Malliarou et al 2016 [34], the most emotional reaction was anger. Due to DB, participants did not consider interactions between themselves and physicians as desirable, which was consistent with the study by Prati and Pietrantoni 2014 [35]. In his study, Sonada 2018 [25] had found working with a key person such as a surgeon and close relationship with him as one of the stressful team factors for a scrub nurse, in a way that DBs could redouble this stress.

Ignoring nurses' knowledge, experiences, and assistance as found in this study, it has been common in other studies. Ignoring the abilities of nurses is one of the important types of uncivil behavior it was reported in studies of Yazdimoghaddam, H. Ahanchian M. R. and Sanogoo et al 2017 [36, 37] 
Another category obtained in this study was Role subtraction, surgeon DB caused problems such as loss of concentration, memory impairment, increasing error, lower speed of performance and in general decreasing physical and mental performance. Riskin et al 2019 [38] showed that incivility affects cognitive function by reducing recall of tasks and analytical skills also impairing quality of performance.

Another sub category was indifference and reduced commitment to duties. Although the concept of commitment is complex, a definition of commitment is Obligation to Practical duties, without any Monitoring by system and dedication to the Professional values[39], hang et al 2019 [40] consider factors such as personality affirmation, respect, and independence in the workplace as resources of commitment. Therefore, it is very important to pay attention to reducing the factors that destroy commitment to duties.

\section{Unfriendly behaviors and tension with co-workers}

Some participant mentioned aggression to colleagues as an effect of DB, Grissinger 2017 [41] emphasized environments affected by DBs cause hostile behavior toward each other.

\section{Deviated focus from patients to the surgeon}

The present study also confirmed the findings by Cochran and Elder 2015 [5] in which DBs could lead to negative consequences such as shifting attention from patients to surgeons.

In Escape to a safe margin as a main category participants mentioned it as an important and most common reaction to DBs that included silence and avoidance of disruptive situations. This reaction augmented by low support and caused moving towards the silence and trying self-protection by lack of presence in the room of disruptive surgeon or leaving job. However, the most significant effect of such behaviors in the study by Cochran and Elder [5] was avoidance from the disruptive actors.

Silence as an important subgroup could lead to limitation and no utilizing abilities and talents. In the phenomenon of silence whose incidence rate has been increasing in nursing in recent years, the nurses do not share ideas related to technical or behavioral problems for some such as rejection, lack of support, and fears of disrespect. Silence is usually manifested following reduced motivation and causes serious threats for patient safety and care. In a study about silence, midwives and, nurses stated that there was more silence on ethical issues and responsibility[42]. Therefore, it is critical to address and prevent it [43]. Silence as a Consequence of DBs was also in line with the findings of Chrouser and Partin 2019 [6].

Adaptation to stay calm was basically built on relying and reinforcing on mora/ values was considered as the main adaptive strategy to mitigate the effects of DBs. Indeed, adaptation to stay calm by reinforcing ethics and paying attention to the call of conscience in nurses and considering patients as important family members such as siblings or parents or working to please God to overcome negative effects of destructive behaviors and other discouraging interactions had not been so far reported in the related literature.

\section{Trying to get support from authorities and co-workers}

reporting to head nurses and sometimes talk to a co-worker in the hope of finding a way to reduce the mentioned behaviors and getting support. But, in the study by Cochran and Elder 2015 [5], interacting with co- workers for finding support and warning others was used as a key strategy.

Most participants considered that DBs could have negative effects on motivation and performance, and some nurses regarded them as a factor to Attempts to develop capabilities (skills and spirit), such as the better and more accurate provision of the requirements for surgeons and surgery and attempts to increase their knowledge to protect themselves, which was in agreement with the study by Chrouser and Partin, 2019 [6]. This may be due to differences in individuals' perceptions or adaptive strategies.

Participants sometimes tried not to be upset by the DB and did not take it negatively. They "Attributed behaviors to external factors such as severity and difficulty of the surgery or problems such as equipment failure. In the study of Cochran and Elder 2015[5] 
also externalizing the behavior was one of the main coping strategies used by the participant. This means the surgeon's behavior was not reflective of their own work performance.

Another main effect of DB obtained in this study was indirect confrontation including decreasing cooperation and no support from the surgeon and Punishment of Surgeon In the current study confrontation was indirectly that means, participants did not directly protest to disruptive surgeons. But decreased their cooperation and support from the surgeon. The surgeon's DBs as a leader of the team cause reducing the sense of engagement in the surgery team because of ignoring oneself as a team member. This concept was consistent with the study of Hosseinpour Dalenjan et al 2017 [11] that reported similar results in nurses. They found that "dedication", as a dimension of nurses' work engagement, had decreased due to incivility, especially the incivility of physicians. "Engagement was defined as a positive, fulfilling, work-related state of mind that is characterized by vigor, dedication, and absorption. Dedication refers to being strongly involved in work and experiencing a sense of significance, enthusiasm, inspiration" [44].

Punishment of Surgeon also was another strategy that lower used by the participants. Karatuna 2015 [45] noted in active strategies against DB victims relied on confrontation strategies such as standing up or threatening to the bad actor. In the current study, it happened but indirectly. Excellent cooperation in ORs also requires eliminating hierarchical structure and supporting personnel. Moreover, developing a culture of mutual support and respect allows for safer services [46].

\section{Conclusions}

The findings of the present study illustrated the different effects of DBs on ORNs and Strategies used by employees, and provided a relatively good vision to staff, managers, and surgeons and also highlighted the importance of preventing these behaviors.

Nurses provided valuable information about the impacts and consequences of such behaviors. Discovering issues such as DBs and their causes and effects can be thus considered as an opportunity to reform the trends that lead to such unpleasant events and benefit them as a chance to prevent abuses. A distance in the team for any reason can also jeopardize patient safety and quality of care. Therefore, identifying the effects of DBs regarding their consequences on teams and the performance of team members is essential. Because some individuals unaware of the undesirable impacts of these behaviors or their atmosphere can unwantedly cause adverse effects on the OR team and its performance. As team members strive to improve their technical skills, it is also important to strive to improve team skills and team dynamics. The OR is a big family and should also move towards creating a happy family and provide the grounds for staff interactions and comfort.

Therefore, strengthening factors such as respect to each other's that contribute to team cohesion and team engagement is one of the most important issues in performing successful and safe surgeries.

Organizations can take an effective step in improving working relationships by follow-up these behaviors, and surgeons as team leaders who play a key role in team cohesion can help improve the performance of members by promoting leadership styles and reducing DBs while respecting the roles of nurses and ultimately improve the quality of patient care.

\section{Limitations}

Concerning the qualitative nature of this study, its generalization was done cautiously, although there were attempts to sample the data from different ORs and ORNs with a wide variety of backgrounds, levels of education, and shifts to provide trustworthiness. In addition, the lack of a survey on the causes of DBs as well as time limitations was considered as other limitations to the present study. Therefore, future investigations are suggested to examine the causes of DBs from the perspective of different groups involved in ORs and to reflect on the effects of DBs on other team members such as nurse anesthetists and anesthesiologists as well as students. It also seems necessary to design and implement a training program to evaluate the effects on changing DBs.

\section{Abbreviations}

OR 
Operating room

ORNs

Operating room nurses

DB

Disruptive Behavior

DBs

Disruptive Behaviors

\section{Declarations}

\section{Authors' contributions}

All authors (SM, MP, FA-SH, and AHP) contributed to conception and design of the study, SM collected the data, SM, MP and AHP analyzed the data, FA-SH an MS analysis and interpretation of the data, FA-SH an MS drafted the article, all authors approved the final version.

\section{Acknowledgments}

The authors thank the ORNs who shared their valuable experiences.

\section{Funding}

There is no financial support for this research, authorship, designing, data collection or, data analysis and publication.

\section{Availability of data and materials}

The datasets analyzed during (interviews and transcriptions) the current study are not publicly available due to commitment to data confidentiality to participants but are available from the corresponding author on reasonable request.

\section{Consent for publication}

This article does not include the details of the individuals, and the participants declare their approval to publish with confidentiality.

\section{Competing interests}

The authors declare that they have no competing interests.

\section{Ethics approval and consent to participate}

This study was approved by the Committee of Ethics in Medical Research at Shahid Beheshti University of Medical Sciences with Code No: IR.SBMU.PHARMACY.REC.1397.179. The data were collected after obtaining the required permits by referring to the ORs of university hospitals, explaining the purpose of the study, obtaining written informed consent from the participants, providing an explanation about voluntary participation and the possibility of withdrawal at any stage of the study. The confidentiality of information was also assured.

\section{References}

1. Cochran A, Elder WB. A Model of Disruptive Surgeon Behavior in the Perioperative Environment. J Am Coll Surg. 2014;219:390-8.

2. Katz MG, Rockne WY, Braga R, McKellar S, Cochran A. An improved patient safety reporting system increases reports of disruptive behavior in the perioperative setting. Am J Surg. 2020;219:21-6.

3. Layne DM, Nemeth LS, Mueller M, Schaffner MJ, Stanley KM, Martin MM, et al. Negative behaviours in health care: Prevalence and strategies. J Nurs Manag. 2019;27:154-60.

4. Villafranca A, Magid K, Young A, Fast I, Jacobsohn E. Abusive behaviour in Canadian and US operating rooms. Can J Anaesth. 2019;66:795-802.

5. Cochran A, Elder WB. Effects of disruptive surgeon behavior in the operating room. Am J Surg. 2015;209:65-70.

6. Chrouser KL, Partin MR. Intraoperative Disruptive Behavior: The Medical Student's Perspective. J Surg Educ. 2019;76:123140. 
7. Lee MJ. On Patient Safety: Being a Jerk in the Operating Room is Bad for the Patient. Clin Orthop Relat Res. 2017;475:32830.

8. Villafranca A, Hiebert B, Hamlin C, Young A, Parveen D, Arora RC, et al. Prevalence and predictors of exposure to disruptive behaviour in the operating room. Can J Anaesth. 2019;66:781-94.

9. Fast I, Villafranca A, Henrichs B, Magid K, Christodoulou C, Jacobsohn E. Disruptive behaviour in the operating room is underreported: an international survey. Can J Anaesth. 2020;67:177-85.

10. Kusy M, Holloway EL. A field guide to real-time culture change: just "rolling out" a training program won't cut it. The Journal of medical practice management: MPM. 2014;29:294-303.

11. Hosseinpour Dalenjan L, Atashzadeh Shoorideh F, Hosseini M, Mohtashami J. The Correlation Between Nurse's Work Engagement and Workplace Incivility. Iran Red Crescent Med J. 2017;19:1-8.

12. Rosenstein AH, O'Daniel M. Disruptive behavior and clinical outcomes: perceptions of nurses and physicians. Am J Nurs. 2005;105:54-64. quiz - 5.

13. Garth K, Mailow T, Armstrong N, Todd D, Byers D. Nurses' Perceptions of Incivility in the Operating Room. Madridge J Nurs. 2019;4:164-6.

14. Longo J. Combating Disruptive Behaviors: Strategies to Promote a Healthy Work Environment Online. J Issues Nurs. 2010;15:1-12.

15. Rosenstein A. Disruptive and Unprofessional Behaviors. In: Brower KJ, Riba MB, editors. Physician Mental Health and WellBeing: Research and Practice. Cham: Springer International Publishing; 2017. pp. 61-85.

16. The, joint, commission. Sentinel Event Alert. Behaviors that undermine a culture of safety. (2008).http://www.methodisthealthsystem.org/documents/Medical\%20Staff/Sentinel\%20Event\%20Alert\%20lssue\%2040.pdf. Accessed 21 July 2019.

17. World, Health, Organization. Safe Surgery. Why safe surgery is important. (2019).https://www.who.int/patientsafety/safesurgery/en/. Accessed 17 March 2019.

18. Chrouser KL, Xu J, Hallbeck S, Weinger MB, Partin MR. The influence of stress responses on surgical performance and outcomes: Literature review and the development of the surgical stress effects (SSE) framework. Am J Surg. 2018;216:57384.

19. John PR, Heitt MC. Disruptive Physician Behavior: The Importance of Recognition and Intervention and Its Impact on Patient Safety. Am J Hosp Med. 2018;13:210-2.

20. Rosenstein AH. Physician disruptive behaviors: Five year progress report. World J Clin Cases. 2015;3:930-4.

21. Maddineshat M, Hashemi M, Tabatabaeichehr M. Evaluation of the disruptive behaviors among treatment teams and its reflection on the therapy process of patients in the operating room: The impact of personal conflicts. J Educ Health Promot. 2017;6:1-5.

22. Park KO, Park SH, Yu M. Physicians' Experience of Communication with Nurses related to Patient Safety: A Phenomenological Study Using the Colaizzi Method. Asian Nurs Res (Korean Soc Nurs Sci). 2018;12:166-74.

23. Hopkins J, Hedlin H, Weinacker A, Desai M. Patterns of Disrespectful Physician Behavior at an Academic Medical Center: Implications for Training, Prevention, and Remediation. Acad Med. 2018;93:1679-85.

24. Keller S, Tschan F, Semmer NK, Timm-Holzer E, Zimmermann J, Candinas D, et al. "Disruptive behavior" in the operating room: A prospective observational study of triggers and effects of tense communication episodes in surgical teams. PloS one. 2019;14:1-16.

25. Sonoda Y, Onozuka D, Hagihara A. Factors related to teamwork performance and stress of operating room nurses. J Nurs Manag. 2018;26:66-73.

26. Vogelsang A-C, Swenne C, Gustafsson B, Falk-Brynhildsen K. Operating theatre nurse specialist competence to ensure patient safety in the operating theatre: A discursive paper. Nursing Open. 2019;7:495-502.

27. Hsieh HF, Shannon SE. Three approaches to qualitative content analysis. Qual Health Res. 2005;15:1277-88.

28. Graneheim UH, Lundman B. Qualitative content analysis in nursing research: concepts, procedures and measures to achieve trustworthiness. Nurse Educ Today. 2004;24:105-12.

Page $13 / 14$ 
29. Morse J. Critical Analysis of Strategies for Determining Rigor in Qualitative Inquiry. Qual Health Res. 2015;25:1212-22.

30. Safiri K, Mansoirian Ravandi F. Gender Clichés and Social Health: a Study on Men and Women from Tehran. Women's Psychological Social Studies. 2015;13:66-73..[In persian].

31. Roche AM, Dubowitz G. In: Ferreres A, editor. Surgical Ethics. Springer, Cham. The Anesthesiologist and the Surgeon: Two Professionals Sharing the Command of the Patient in the Operating Room: Springer, Cham; 2019. pp. 159-68.

32. Grade MM, Tamboli MK, Bereknyei Merrell S, Mueller C, Girod S. Attending Surgeons Differ From Other Team Members in Their Perceptions of Operating Room Communication. J Surg Res. 2019;235:105-12.

33. Hassan El-Amrosy S, Mamdouh Elkholy S, Ebrahim Elshall S. The Effect of Educational Intervention about Incivility on Psychological Wellbeing and Burnout among Nurses. American Journal of Nursing Research. 2019;7:1069-77.

34. Malliarou M, Karathanasi K, Sarafis P, Prezerakos P, Koutelekos J. Violence and Aggression in Operating Room. Occup Med Health Aff. 2016;4:1-4.

35. Prati G, Pietrantoni L. Attitudes to teamwork and safety among Italian surgeons and operating room nurses. Work. 2014;49:669-77.

36. Sanagoo A, Yazdani S, Jouybari L, Kalantari S. Uncivil Behaviors in Nursing Workplace: A Qualitative Study. J Nurs Educ. 2017:4:41-9.

37. Yazdimoghaddam H. R. AM. Explanation The Pergormance of Operating Room Technesian:A Qualitative Study. J Mazandaran Univ Med Sci. 2016;26:121 - 34(Persian).

38. Riskin A, Bamberger P, Erez A, Foulk T, Cooper B, Peterfreund I, et al. Incivility and Patient Safety: A Longitudinal Study of Rudeness, Protocol Compliance, and Adverse Events. Jt Comm. J Qual Patient Saf. 2019;45:358-67.

39. Shali M, Joolaee S, Hooshmand A, Haghani H, Masoumi H. The Relationship between Incidence of Patient Falls and Nurses'. Professional Commitment Hayat. 2016;22:27-37.

40. Chang H-Y, Lee I-C, Chu T-L, Liu Y-C, Liao Y-N, Teng C-I. The role of professional commitment in improving nurses' professional capabilities and reducing their intention to leave: Two-wave surveys. J Adv Nurs. 2019;75:1889-901.

41. Grissinger M. Disrespectful Behavior in Health Care: Its Impact, Why It Arises and Persists, And How to Address It-Part 2. P \& T: a peer-reviewed journal for formulary management. 2017;42:74-7.

42. Gkorezis $P$, Panagiotou $M$, Theodorou $M$. Workplace ostracism and employee silence in nursing: the mediating role of organizational identification. J Adv Nurs. 2016;72:2381-8.

43. Yurdakul M, Beşen MA, Erdoğan S. The organisational silence of midwives and nurses: reasons and results. J Nurs Manag. 2016;24:686-94.

44. Schaufeli WB, Bakker AB. Utrecht work engagement scale: Preliminary manual. Occupational Health Psychology Unit. Utrecht University. (2004).https://www.wilmarschaufeli.nl/publications/Schaufeli/Test\%20Manuals/Test_manual_UWES_English.pdf. Accessed 26 January 2020.

45. Karatuna I. Targets' coping with workplace bullying: a qualitative study. Qualitative Research in Organizations and Management. An International Journal. 2015;10:21-37.

46. Wakeman D, Langham MR. Jr. Creating a safer operating room: Groups, team dynamics and crew resource management principles. Semin Pediatr Surg. 2018;27:107-13. 